\title{
PERAN BADAN AMIL ZAKAT NASIONAL (BAZNAS) DALAM MEMBANTU MASYARAKAT KURANG MAMPU DI DAERAH LOMBOK TIMUR
}

\author{
Saefuddin \\ Institut Agama Islam Hamzanwadi NW Lombok Timur \\ Email: saeffiqri@gmail.com
}

\begin{abstract}
Abstrak: Penelitian ini bertujuan untuk menjelaskan bagaimana efisiensi peran BAZNAS dalam membantu masyarakat kurang mampu khususnya di daerah Lombok Timur. Jenis penelitian ini menggunakan pendekatan kualitatif- deskriptif. Hasil Penelitian ini menunjukkan bahwa pada masa kepengurusan periode ini, BAZNAS Lombok Timur mereformasi program pengelolaan BAZNAS dengan semangat transparansi dan akuntabel.Sumber- sumber zakat, infak, dan sadaqoh digali dan dikembangkan .Upaya ini didukung oleh kebijakan Pemda yang menghimbau segenap jajarannya, termasuk para pengusaha yang berada di Wilayah Lombok Timur agar mengeluarkan zakat, infak dan sadaqoh melalui BAZNAS. Dalam melaksanakan tugasnya BAZNAS Lombok Timur memiliki beberapa tim relawan di tengah- tengah masyarakat sebagai pemberi informasi kepada masyarakat tentang program- program BAZNAS Lombok Timur. Sehingga para muzakki lebih mudah untuk menyalurkan bantuan/ zakatnya dan para mustahiq lebih mudah untuk mendapatkan bantuan/ zakat tersebut.
\end{abstract}

Kata Kunci : BAZNAS dan Masyarakat Kurang Mampu

\begin{abstract}
This study aims to explain how efficient BAZNAS's role is in helping underprivileged communities, especially in the East Lombok area. This type of research is a qualitativedescriptive approach. The results of this study indicate that during the stewardship of this period, BAZNAS East Lombok reforms the BAZNAS management program with a spirit of transparency and accountability. Entrepreneurs who are in the East Lombok Region have to pay zakat, infaq and sadaqoh through BAZNAS. In carrying out its duties, BAZNAS East Lombok has several volunteer teams in the midst of the community to provide information to the community about BAZNAS East Lombok programs. So that it is easier for muzakki to distribute their assistance / zakat and it is easier for the mustahiq to get this assistance / zakat.
\end{abstract}

Keywords: BAZNAS and Poor People 


\section{PENDAHULUAN}

Badan Amil Zakat Nasional (BAZNAS) Lombok Timur sebagai bagian dan pranata keagamaan membuktikan peran itu di satu pihak, di samping peran elemen lain dalam masyarakat Lombok timur, Bersama elemen masyarakat yang lain, BAZNAS Lombok Timur secara istiqomah berusaha meningkatkan taraf hidup masyarakat Lombok Timur dalam berbagai bidang kehidupan secara bertahap. BAZNAS Lombok Timur meski dengan usia belia telah banyak melakukan upaya untuk melepas masyarakat dari jeratan kemiskinan dan keterbelakangan dengan berbagai macam kegiatan seperti bantuan modal untuk orang miskin yang mempunyai kemampuan dan keterampilan untuk berrdagang, beternak, dan bertani.

Untuk menindak lanjuti Undangundang no. 38/ 1999 tentang pengelolaan zakat, maka pemerintah kabupaten Lombok Timur membuat perda No. 9/ 2002. Sejak dikeluarkan sampai jabatan terakhir belum sempat dijalankan. Sejauh yang dapat diamati, kendalanya adalah tidak adanya prosedur baku untuk mengoperasikan Perda tersebut. Namun, pasca terpilihnya Bupati Lombok Timur tahun 2003, membawa angin segar bagi dunia perzakatan di Lombok Timur. Gagasan pelaksanaan program zakat ini tidak lepas dari peran H. Moh. Ali bin Dachlan yang juga pendiri LSM terbesar di Lombok Timur yaitu Yayasan Swadaya Membangun (YSM) Mataram. Pada yayasan tersebut, para karyawan menyisihkan gajinya untuk zakat yang dalam istilah mereka disebut sebagai kontribusi staf untuk membantu orang- orang yang kurang mampu.

Tanpa Undang- undang dan Perda, system zakat sudah bisa dijalankan jika saja semua umat islam memahami dan menyadari bahwa zakat adalah suatu kewajiban bagi setiap individu yang mampu. Jika zakat adalah kewajiban harta, maka sholat adalah kewajiban badan yang wajib ditunaikan oleh siapapun yang mengaku dirinya muslim. Namun sayang, apa yang diwariskan oleh Nabi Muhammad SAW. Tersebut diabaikan oleh umat islam itu sendiri. Justru system ini malah dipraktikkan oleh non- muslim dengan istilah yang berbeda, seperti sponsorship, philantrophy, charity, dan lain- lain. Bahkan timbul kesan, seolah- olah system zakat ini hanya bisa dilaksanakan bila berada di Negara Islam.

BAZNAS Lombok Timur lahir 1 tahun setelah terbitnya Perda No. 9 tahun 2002 dan 3 tahun setelah keluarnya Undangundang no. 38/ 1999 tentang pengelolaan zakat. BAZNAS Lombok Timur lahir setelah terjadi suksesi kepemimpinan di Kabupaten Lombok Timur dari Bupati Sahdan ke Bupati pengganti M. Ali Bin Dachlan. Prakarsa Bupati ini lahir karena BAZIS yang sudah ada belum berjalan maksimal. Melihat kondisi inilah Bupati M. Ali Bin Dachlan membentuk BAZNAS yang menggantikan peran BAZIS yang selama ini statis. BAZNAS yang baru ini diketahui oleh Drs. Machsun Said R. 
Sebagai daerah yang hampir $100 \%$ muslim, wajar bila Bupati Lombok Timur mencanangkan system zakat sebagai sebuah gerakan bagi masyarakat di Lombok Timur yang masuk kategori mayoritas miskin (60\% penduduk miskin) untuk mengentaskan atau paling tidak meminimalisir kemiskinan di "Bumi Patuh Karya" ini. Usaha ini tidak siasia karena sudah cukup banuyak panti asuhan dan masyarakat yang kurang mampu bahkan masyarakat miskin yang telah menikmati zakat, infak, dan sedekah ini.

Besarnya jumlah penduduk Muslim di Indonesia diharapkan dapat semakin mengoptimalisasikan peran zakat dalam mengentaskan kemiskinan. Pengelolaan zakat di Indonesia diserahkan kepada BAZNAS dan LAZ. Kerjasama yang baik dari semua lembaga pengelola zakat sangat diperlukan untuk lebih mengoptimalisasikan dana zakat agar dapat mewujudkan peran zakat sebagai solusi untuk menangani masalah kemiskinan di Indonesia terlebih lagi di daerah Lombok Timur.

Pengelolaan dan pendistribusian dana zakat yang dikelola secara amanah, professional, dan tepat sasaran diharapkan akan mengubah mustahik menjadi muzaki. Sehingga zakat dapat memecahkan masalah kemiskinan dengan cara memberdayakan orang-orang yang kurang mampu agar menjadi lebih produktif dan sejahtera.

\section{METODE PENELITIAN.}

\section{Pendekatan Penelitian}

Pendekatan yang digunakan dalam penelitian ini adalah pendekatan kualitatif yaitu suatu prosedur penelitian yang menghasilkan data deskriptif berupa ucapan atau tulisan dan prilaku yang dapat diamati dari orang-orang (subyek) itu sendiri. Dengan pendekatan penelitian kualitatif ini, semua fakta berupa kata-kata lisan maupun tulisan dari sumber data masyarakat Kabupaten Lombok Timur yang menjadi binaan Badan Amil Zakat Nasional (BAZNAS) Kabupaten Lombok Timur yang telah diamati dan dokumen terkait lainnya dari BAZNAS Kabupaten Lombok Timur disajikan dan digambarkan apa adanya untuk selanjutnya ditelaaah guna menemukan.

Sedangkan jenis penelitian yang digunakan adalah studi kasus. Secara teknis studi kasus adalah suatu penelitian yang menyelidiki fenomena dalam konteks kehidupan nyata bilamana batas-batas antara fenomena dan konteks tidak tampak dengan tegas, dimana berbagai sumber bukti dimanfaatkan. Adapun yang menjadi studi kasus dalam penelitian ini adalah mengenai Peran Badan Amil Zakat Nasional (BAZNAS) dalam membantu masyarakat kurang mampu di daerah Lombok Timur.

\section{Sumber Data}

Data adalah sekumpulan bukti atau fakta yang dikumpulkan dan disajikan untuk tujuan tertentu. Data juga dapat diartikan sebagai semua keterangan yang di peroleh 
dari orang yang di jadikan informan maupun yang berasal dari dokumen-dukumen baik dalam bentuk statistik atau dalam bentuk lainnya guna keperluan penelitian itu. Data Kualitatif adalah data yang dinyatakan dalam bentuk kalimat atau uraian. Data ini mempunyai peranan untuk menjelaskan secara deskriptif suatu masalah. Adapun sumber data adalah dari mana data di peroleh. Sumber data penelitian ini terdiri dari dua macam yaitu Sumber Data Primer dan Sumber Data Sekunder.

\section{Teknik Pengumpulan Data}

Metode pengumpulan data adalah caracara yang dapat digunakan oleh peneliti untuk mengumpulkan data. Prosedur pengumpulan data dapat juga di artikan sebagai suatu usaha sadar untuk megumpulkan data yang di perlukan dan dilakukan secara sistematis dengan prosedur yang setandar. Agar dalam penelitian ini dapat di peroleh data-data yang relevan, peneliti menggunakan beberapa metode pengumpulan data yaitu:. Metode Observasi, Metode Wawancara (Interview), dan Metode Dokumentasi.

\section{Teknik Analisis Data}

Analisis data disebut juga pengolahan data dan penafsiran data. Analisis data merupakan upaya mencari dan menata secara sistematis catatan hasil obsevasi, wawancara dan lainnya untuk meningkatkan pemahaman peneliti tentang kasus yang diteliti dan menyajikan sebagai temuan bagi orang lain. Sedangkan untuk meningkatkan pemahaman tersebut analisis perlu dilanjutkan dengan berupaya mencari makna. Analisis data penelitian kualitatif bersifat interactive (berkelanjutan) dan dikembengkan sepanjang program. Analisis data dilaksanakan mulai penetapan masalah, pengumpulan data dan setelah data terkumpulkan.

\section{PEMBAHASAN}

Hasil penelitian ini menunjukkan bahwa peran badan amil zakat nasional (BAZNAS) dalam membantu masyarakat kurang mampu di daerah lombok timur sebagai berikut:

\section{Program Penghimpun ZIS}

Penghimpun dana ZIS dilakukan dengan berbagai macam cara diantaranya adalah sebagai berikut :

1. BAZNAS melakukan penghimpunana zakat dengan cara memotong 2,5\% dari gaji kotor yang diterima oleh setiap PNS/ guru di lingkungan Pemda Kabupaten Lombok Timur yang berjumlah 10.800 orang (kecuali tenaga honorer). Dengan merujuk perintah Bupati. Pemotongan dilakukan langsung di bank pembayar gaji (Bank NTB Cabang Selong). Jadi, tidak dipotong oleh juru bayar pada dinas/ instansi bersangkutan.

2. Instansi pemerintah di luar Pemda (Ventikal), BUMN, dan organisasi profesi lainnya baru sebatas diberikan seruan oleh Bupati. Saat ini, sedang dipertimbangkan adanya revisi Perda yang dapat memberikan sanksi bagi yang mengelak dari kewajiban berzakat. 
3. Walaupun dalam Perda juga diamantkan adanya Badan Amil Zakat Kecamatan, namun dalam praktik BAZDES/ BAZKEL yang lebih didorong untuk berperan. BAZNAS mendorong terbentuknya BAZ di tingkat desa/ kelurahan karena masyarakat desa dan kelurahan merupakan ujung tombak dan sasaran pembangunan.

4. BAZDES/ BAZKEL berhak memungut zakat dan hasil pertanian, perdagangan, dan zakat lainnya dari masyarakat umum yang tinggal di mana BAZDES/ BAZKEL berada.

5. Dengan panduan BAZNAS kabupaten, setiap BAZDES/ BAZKEL diberikan kewenangan penuh dalam membangununit pengumpulan zakat yang sesuai dengan desa/ kelurahan, baik melalui masjid, kepala dusun, dan lain- lain. Yang penting,prosesnya berjalan dengan tertib, dalam arti adanya pencatatan jumlah zakat terkumpul, asal, dan sasarandistribusi.

\section{Program Pendayagunaan ZIS.}

BAZNAS Lombok Timur berupaya agar program pendayagunaan dilaksanakan dengan prinsip- prinsip yang berlaku secara modern dalam arti sesuai standar lembagalembaga internasional, misalnya adanya transparansi, profesionalitas, dan akuntabelitas. Ada beberapa program pendayagunaan ZIS di BAZNAS Lombok Timur. Walaupun belum semua terlaksana, namun secara umum dana zakat diperuntukkan untuk pembiayaan antara lain adalah:
1. Usaha ekonomi produktif seperti bantuan untuk kegiatan ekonomi produktif yang bersifat menciptakan lapangan kerja bagi kelompok dan bersifat padat karya, bantuan dalam bentuk alat dan barangbarang bagi mereka yang memiliki potensi, kerjasama investasi bagi hasil dengan mitra usaha yang mempekerjakan orang miskin, bantuan ekonomi produktif untuk muallaf. Sifat bantuan dalam program ini harus bersifat mendidik. Diberikan dengan system dana bergulir serta pendampingan untuk memperoleh modal. Kegiatan yang dapat dibantu adalah usaha ekonomi produktif oleh suatu kelompok dalam bentuk kegiatan industri kecil, industri rumah tangga, kegiatan yang bersifat memberikan nilai tambah bagi produk komoditi dan memiliki perputaran modal yang kontinyu, dan memberikan pendapatan setiap hari. Termasuk di sini adalah kelompok pedagang bakulan, pedagang kaki lima, dan lain- lain.

2. Bantuan Konsumtif, seperti bantuan rutin/ bulanan untuk konsumsi panti asuhan, bantuan Beasiswa bagi anak keluarga miskin, bantuan bagi guru honor pada sekolah- sekolah swasta, bantuan santunan bagi orang tua jompo nonproduktif yang terlantar, Emergency seperti Bantuan yang di disalurkan kepada orang miskin yang sakit dan tertimpa musibah, Revolving Fund (kerja sama dengan Bank Syari'ah) seperti Program Qardul hasan untuk bantuan modal, program pelunasan/ 
pengalihan hutang dengan system bebas bunga bagi masyarakat desa dan juga bagi muzakki (PNS/ Guru) dalam kondisi darurat.

\section{SIMPULAN}

Berdasarkan hasil penelitian tersebut, maka dapat disimpulkan bahwa Badan Amil Zakat Nasional (BAZNAS) Lombok Timur sebagai bagian dari pranata keagamaan selalu berupaya bagaimana cara untuk mengoptimalkan membantu masyarakatmasyarakat yang kurang mampu/ miskin yang ada di Lombok Timur ini. Dalam melaksanakn tugasnya sebagai pengumpul dan penyalur zakat, Badan Amil Zakat Nasional (BAZNAS) Lombok Timur mengharapkan kerja sama dari berbagai elemen masyarakat terutama dari pengurus desa/ kelurhan sehinga BAZNAS Kabupaten dapat terbantu oleh BAZDES/ BAZKEL. Karena dengan adanya BAZDES/ BAZKEL akan lebih memudahkan masyarakat yang statusnya sebagai muzakki untuk menyalurkan Zakatnya ke BAZNAS Kabupaten dan masyarakat yang statusnya sebagai mustahiq akan lebih mudah megakses/ mendapatkan dana zakat tersebut.

Selain dengan mengaktifkan BAZNAS/ BAZKEL, dalam mensosialisasikan programnya, BAZNAS Lombok Timur menggunakan media social sebagai alat untuk memeberikan informasi kepada masyarakat dan juga BAZNAS Lombok Timur mempunyai tim relawan yang berada di tengah- tengah masyarakat yang tentunya tim relawan ini ada apabila BAZ tingkat Desa/ Kelurahan diaktifkan. Yang dimana Tim relawan inilah yang sebagai penyambung lidah untuk membantu dan memberikan informasi terkait program-program dari BAZNAS Kabupaten Lombok Timur. Dalam mendukung keaktifan BAZDES/ BAZKEL, Badan Amil Zakat Nasional (BAZNAS) Lombok Timur dalam satu kali setahun mengadakan semacam penyuluhan atau sosialisasi kepada Kepala Desa/ Kelurahan Se- Lombok Timur untuk meningkatkan kinerja dari BAZDES/ BAZKEL untuk membantu berjalanya program dari BAZNAS kabupaten sebagai pengumpul dan penyalur zakat kepada Ashnaf yang telah ditentukan.

\section{DAFTAR PUSTAKA}

Ali, M. Daud dan Daud, Habibah. 1995. Lembaga-Lembaga Islam di Indonesia. Jakarta: RajaGrafindo Persada.

Arikunto, Suharsimi. 2000. Manajemen Penelitian. Jakarta: Rineka Cipta.

Ash-Shiddieqy, M. Hasbi. 2006. Pedoman Zakat, Pustaka Rizki Putra, Semarang,

Asnaini. 2008. Zakat Produktif dalam Perspektif Hukum Islam. Yogyakarta: Pustaka Pelajar.

Departemen Agama Republik Indonesia. 2007. Al Qur'an dan Terjemahannya. Surabaya: Mega Jaya Abadi.

Hafiduddin, Didin. 2002. Zakat dalam Perekonomian Modern, Jakarta :Gema Insani Press 
Hamid, Syamsul Rizal. 2006. Petuah Rasulullah Saw. Seputar Masalah Zakat \& Puasa: Cahaya Salam.

Mahfudh, Sahal. 1994. Nuansa Fiqih Sosial. Yogyakarta: LkiS.

Moleong, Lexy J. 2001. Metode Penelitian Kualitatif. $\quad$ Bandung: Remaja Rosdakarya.

Qardhawi, Yusuf. 2005. Spektrum Zakat dalam Membangun Ekonomi Kerakyatan. Jakarta: Zikrul Hakim.

Supani. 2010. Zakat di Indonesia: Kajian Fikih dan Perundang-Undangan. Yogyakarta: Grafindo Lentera Media. 